\title{
Copolymerization of Ethylene/1-Olefin with Mesoporous Titania-Supported Zirconocene/MAO Catalyst
}

\author{
Somchat Amornlertpreecha ${ }^{1}$, Takeshi Shiono ${ }^{2}$, and Bunjerd Jongsomjit ${ }^{1, *}$ \\ 1 Center of Excellence on Catalysis and Catalytic Reaction Engineering, Department of Chemical \\ Engineering, Faculty of Engineering, Chulalongkorn University, Bangkok 10330,. Thailand \\ 2 Department of Applied Chemistry, Graduate School of Engineering, Hiroshima University, Higashi- \\ Hiroshima 739-8527, Japan \\ *E-mail: bunjerd.j@chula.ac.th
}

\begin{abstract}
Different mesoporous titanias synthesized by hydrolysis and polycondensation reactions of tetrabutyl titanate with various hydrolysis ratios $\left(\mathrm{H}_{2} \mathrm{O} / \mathrm{Ti}\right.$ by mole) were employed as supports for zirconocene/MAO catalysts in ethylene/1-olefin copolymerization. The pure anatase phase of titania was detected by X-ray diffraction (XRD) and the morphology was seen by scanning electron microscopy (SEM). The titania obtained was then impregnated with methylaluminoxane $(\mathrm{MAO})$. The amounts of $[\mathrm{Al}]_{\mathrm{MAO}}$ were measured by energy dispersive X-ray spectroscopy (EDX) and X-ray photoelectron spectroscopy (XPS). The copolymerization of ethylene/1-hexene (EH) and ethylene/1octene (EO) was performed using titania-supported zirconocene/MAO catalysts. Upon polymerization, it was found that the high surface area of titania apparently exhibited high polymerization activity due to large amounts of $[\mathrm{Al}]_{\text {MAO }}$ present as seen by EDX and XPS. The obtained copolymer was further characterized by ${ }^{13} \mathrm{C}$ nuclear magnetic resonance ${ }^{13} \mathrm{C}$ NMR) and differential scanning calorimetry (DSC). It revealed that based on ${ }^{13} \mathrm{C}$ NMR, the random copolymer was obtained for both $\mathrm{EH}$ and $\mathrm{EO}$ systems. However, $\mathrm{EH}$ copolymer exhibited higher melting temperature $\left(\mathrm{T}_{\mathrm{m}}\right)$ than EO copolymer indicating that the EH system had less comonomer incorporation.
\end{abstract}

Keywords: Mesoporous $\mathrm{TiO}_{2}$, polyethylene; copolymerization, zirconocene, methylaluminoxane.

ENGINEERING JOURNAL Volume 16 Issue 5

Received 6 March 2012

Accepted 22 April 2012

Published 1 October 2012

Online at http://www.engj.org/

DOI:10.4186/ej.2012.16.5.9 


\section{Introduction}

Polyethylene is the most commodity plastic frequently seen in daily life due to its various applications. It is the polymer that makes almost everything. Many methods to improve the properties of polymer such as grafting, crosslink and sometimes adding 1-olefin including 1-butene, 1-hexene and 1-octene [1] will provide long chains of polyethylene. This is called linear low-density polyethylene (LLDPE). The development of metallocene catalysts could further help with processing quality to LLDPE [2]. However, it was found that the homogeneous metallocene catalytic system still has some drawbacks; for example, (i) the lack of morphology control of polymer causing the reactor fouling; (ii) the limitation of being able to use only in the solution process, whereas the existing technologies are mainly based on the gas phase and slurry processes; and (iii) it requires a lot of cocatalysts, which cost highly. Hence, binding the metallocene catalyst onto suitable inorganic support is a promising way to overcome these drawbacks [3,4]. One of methods to apply metallocenes for the polymerization of olefin in slurry or gas phase is to immobilize them onto the suitable support. Typical supports are inorganic oxide such as silica, aluminia, titania and zeolite $[5,6]$.

This study focused on synthesis of LLDPE via the in situ polymerization of ethylene/1-olefin (1-hexene and 1-octene) with mosoporous titania-supported zirconocene/MAO catalyst. The mesoporous titania was chosen due to it is easy to synthesize and the mesoporous structure may facilitate the dispersion of cocatalyst upon immobilization. The effect of mesoporous titania-supported catalyst on the catalytic activity and polymer properties was investigated. The main objective of this work was to investigate the influence of different mesoporous titania supports on the catalytic activity and polymer properties. The mesoporous titania supports were synthesized via the gol-gel method having the average pore size of $30 \mathrm{~nm}$ and BET surface areas ranging from 70 to $145 \mathrm{~m}^{2} / \mathrm{g}$.

\section{Experimental}

\subsection{Materials}

Titanium butoxide was purchased from Aldrich chemical company. Absolute ethanol, phosphoric acid $(48 \%)$ was supplied from Carlo Erba. The rac-ethylenebis (indenyl) zirconium dichloride (rac-Et [nnd ${ }_{2} \mathrm{ZrCl}_{2}$ ) was supplied from Aldrich chemical company. Ethylene (99.96\% pure) was donated from the National Petrochemical Co., Ltd., Thailand. 1-Octene (98\%) and 1-Hexene (97\%) were purchased from Aldrich chemical company and purified by distilling over sodium under argon atmosphere before use. Methylaluminoxane (MAO; $20 \mathrm{wt} \%$ ) was donated by the PTT Chem Co., Ltd., Thailand. Trimethylaluminum (TMA, 2 M in toluene) was supplied by Nippon aluminum alkyls, Ltd., Japan. Toluene was dried over dehydrated $\mathrm{CaCl}_{2}$ and distilled over sodium/benzophenone before use. All chemicals and polymerization were manipulated under an argon atmosphere, using a glove box and/or Schlenk techniques. Ultrahigh purity argon was further purified by passing it through columns that were packed with BASF catalyst R3-11G (molecular-sieved to $3 \mathrm{~A}^{\circ}$ ), sodium hydroxide $(\mathrm{NaOH})$, and phosphorus pentaoxide $\left(\mathrm{P}_{2} \mathrm{O}_{5}\right)$ to remove traces of oxygen and moisture.

\subsection{Preparation of Mesoporous Titania}

Mesoporous titanias having different surface areas were prepared according to [7]. First, $3.6 \mathrm{~g}$ of titanium butoxide was dissolved in $25.2 \mathrm{~g}$ of absolute ethanol under stirring. After $15 \mathrm{~min}, 0.48 \mathrm{ml}$ of $0.28 \mathrm{M}$ phosphoric acid was added to the solution mixture and stirred for $3 \mathrm{~h}$ at room temperature. Then, the different amount of deionized water was dropped to the solution under vigorous stirring in order to obtain different surface areas. The hydrolysis ratio $\left(\mathrm{H}_{2} \mathrm{O} / \mathrm{Ti}\right)$ used in this experiment was $10.5,26$ and $42 \mathrm{~mol} \%$. Water and ethanol were then evaporated at ca. $78^{\circ} \mathrm{C}$. The resulting solid was dried overnight in vacuum oven at $80^{\circ} \mathrm{C}$, and calcined at $500^{\circ} \mathrm{C}$ for $3 \mathrm{~h}$ prior to preparation of catalyst precursors.

\subsection{Preparation of Catalyst Precursor by Impregnation Method}

$0.2 \mathrm{~g}$ of mesoporous titania obtained from Sec. 2.2 was reacted with $0.494 \mathrm{ml}$ of $20 \mathrm{wt} \% \mathrm{MAO}$ solution in toluene at room temperature and stirred for $30 \mathrm{~min}$ and evacuated toluene to ensure the removal of impurities for 3 times. The white powder of $\mathrm{MAO} / \mathrm{TiO}_{2}$ was obtained. 


\subsection{Characterization of Support and Catalyst Precursor}

The obtained mesoporous titania was characterized using $\mathrm{N}_{2}$ physisorption to determine pore size, pore size distribution and surface area. X-ray diffraction (XRD) was performed to examine the crystalline phase of titania. Morphologies were observed by scanning electron microscopy (SEM).

The catalyst precursor $\left(\mathrm{MAO} / \mathrm{TiO}_{2}\right)$ was characterized by SEM and energy dispersive X-ray spectroscopy (EDX) to determine distribution of $[\mathrm{Al}]_{\mathrm{MAO}}$ on the $\mathrm{TiO}_{2}$ support and $\mathrm{X}$-ray photoelectron spectroscopy (XPS) to measure the amounts of $[\mathrm{Al}]_{\mathrm{MAO}}$ at surface of $\mathrm{TiO}_{2}$ support.

\subsection{Polymerization of Ethylene/1-Olefin}

Copolymerization of ethylene/1-olefin (1-hexene and 1-octene) was carried out in $100 \mathrm{ml}$ semi-batch stainless steel autoclave reactor with magnetic stirrer. In glove box, the desired amount of rac-Et[Ind $]_{2} \mathrm{ZrCl}_{2}$ and TMA were mixed and stirred for 5 min for aging. Then, the certain amount of catalyst precursor and toluene (to make a total volume of $30 \mathrm{ml}$ ) was introduced into the reactor. After that, the mixture of racEt[Ind $]_{2} \mathrm{ZrCl}_{2}$ and TMA was injected into the reactor. Reactor was brought out of glove box, and then was frozen in liquid nitrogen to stop reaction. The $0.018 \mathrm{~mol}$ of comonomer was introduced into the reactor. The reactor was evacuated to remove argon by vacuum. Then, it was heated up to polymerization temperature of $70^{\circ} \mathrm{C}$ and the polymerization was started by feeding ethylene gas (total pressure of 50 psi in the reactor) until the consumption of ethylene $0.018 \mathrm{~mol}$ was reached (pressure gauge at $6 \mathrm{psi}$ ). The reaction of polymerization was completely terminated by addition of acidic methanol. The time of reaction was recorded for purpose of calculating the activity. The precipitated polymer was washed with methanol and dried at room temperature.

\subsection{Characterization of Copolymer}

The copolymer obtained was further characterized by ${ }^{13} \mathrm{C}$ nuclear magnetic resonance ${ }^{13} \mathrm{C}$ NMR) to determine the triad distribution. Differential scanning calorimetry (DSC) was used to measure the melting temperature.

\section{Results and Discussion}

The characteristics of mesoporous titania prepared using different hydrolysis ratios are shown in Table 1. It can be observed that titania synthesized using hydrolysis ratio of 26 exhibited the highest surface area (145 $\left.\mathrm{m}^{2} / \mathrm{g}\right)$ and pore volume $\left(0.148 \mathrm{~cm}^{3} / \mathrm{g}\right)$. In most case, the nucleation rate of $\mathrm{TiO}_{2}$ increases with increasing the water:alkoxide ratios. As a result, the crystallite size and nanoparticle size should decrease with increasing the water:alkoxide ratios, whereas the surface area increases [8]. However, more amount of water can result in decrease surface area as seen from sample C. All samples exhibited type IV nitrogen adsorption/ desorption isotherms and narrow unimodal pore size distribution (not shown). The average pore size was not affected by the hydrolysis ratios during synthesis.

Table 1. Characteristics of different mesoporous titania.

\begin{tabular}{lcccc}
\hline Sample & $\begin{array}{c}\mathbf{H}_{2} \mathbf{O} / \mathrm{Ti} \\
\text { ratio }\end{array}$ & $\begin{array}{c}\text { BET surface } \\
\text { area }\left(\mathbf{m}^{2} / \mathbf{g}\right)\end{array}$ & $\begin{array}{c}\text { Total pore } \\
\text { volume } \\
\left(\mathbf{c m}^{3} / \mathbf{g}\right)\end{array}$ & $\begin{array}{c}\text { Average pore size } \\
(\mathbf{n m})\end{array}$ \\
\hline $\mathrm{A}$ & 10.5 & 70 & 0.067 & 33 \\
$\mathrm{~B}$ & 26 & 145 & 0.148 & 31 \\
$\mathrm{C}$ & 42 & 100 & 0.111 & 32 \\
\hline
\end{tabular}

$\mathrm{X}$-ray diffraction patterns of all mesoporous titanias are shown in Fig. 1. The XRD peaks at $2 \theta$ values of $25^{\circ}, 38^{\circ}, 48^{\circ}, 54.7^{\circ}, 62.7^{\circ}, 70^{\circ}$ and $76^{\circ}$ were appeared indicating the anatase phase of all titania samples. 


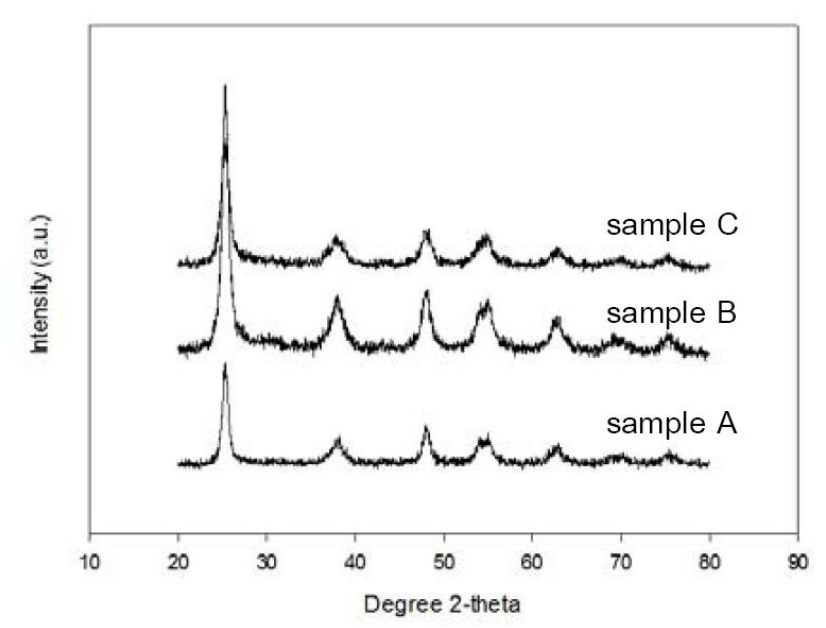

Fig. 1. Wide-angle XRD patterns of mesoporous titania.

Figure 2 shows the SEM image of a typical mesoporous titania sample obtained from this synthesis. No change in morphology was observed upon different hydrolysis ratios. In fact, the morphology of mesoporous titania is fine particulate with particle sizes of ca. $200-500 \mathrm{~nm}$.

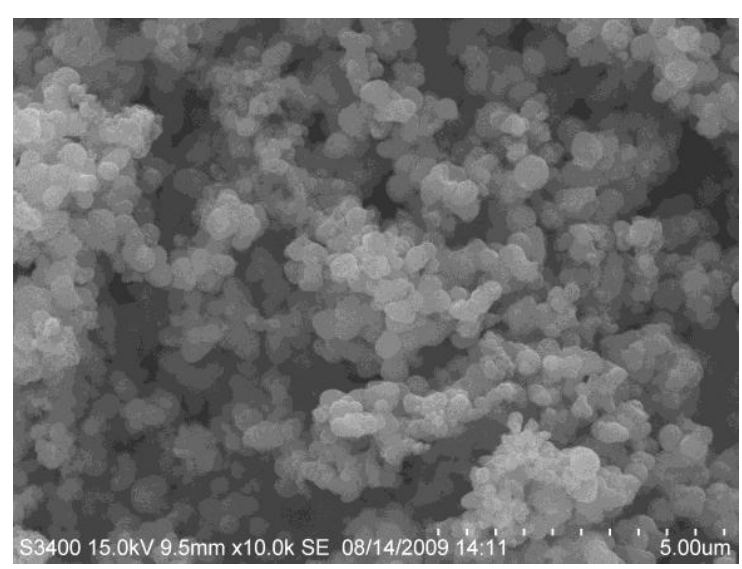

Fig. 2. SEM image of a typical mesoporous titania (Sample B) with 10,000 magnification.

After impregnation of mesoporous titania support with MAO, the SEM/EDX were performed to determine morphology, $[\mathrm{Al}]_{\mathrm{MAO}}$ content and distribution on supports. All samples apparently exhibited the similar morphology. The SEM micrograph and EDX mapping for the typical $\mathrm{MAO} / \mathrm{TiO}_{2}$ sample are shown in Fig. 3. It can be observed that the $\mathrm{MAO}$ was well distributed all over the $\mathrm{TiO}_{2}$ granule as seen by the EDX mapping. The $[\mathrm{Al}]_{\mathrm{MAO}}$ content was also measured using EDX. The amounts of $[\mathrm{Al}]_{\mathrm{MAO}}$ in different $\mathrm{TiO}_{2}$ supports are listed in Table 2. 

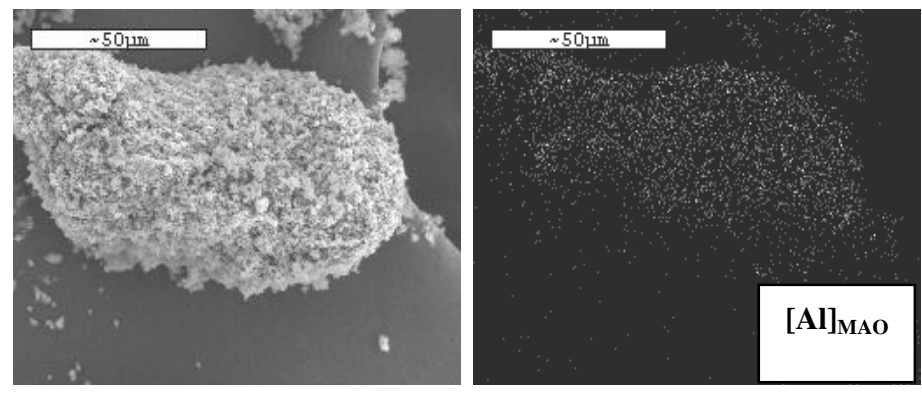

Fig. 3. A typical $\mathrm{MAO} / \mathrm{TiO}_{2}$ sample (Sample B); morphology (left), Al distribution (right).

Table 2. Elemental analysis of $\mathrm{Al}$ and Ti obtained from EDX.

\begin{tabular}{lccc}
\hline Support used & $\begin{array}{c}{[\mathbf{A l}]_{\text {MAO }}} \\
(\% \text { atomic })\end{array}$ & $\begin{array}{c}{[\mathbf{T i}]_{\text {support }}} \\
(\% \text { atomic })\end{array}$ & {$[\mathbf{A l}]_{\text {MAO }} /[\mathbf{T i}]_{\text {support }}$} \\
\hline A & $7.18 \pm 1.48^{\mathrm{a}}$ & $10.25 \pm 2.61^{\mathrm{a}}$ & 0.70 \\
$\mathbf{B}$ & $8.55 \pm 0.97^{\mathrm{a}}$ & $8.92 \pm 0.61^{\mathrm{a}}$ & 0.96 \\
$\mathbf{C}$ & $5.95 \pm 0.76^{\mathrm{a}}$ & $12.08 \pm 1.88^{\mathrm{a}}$ & 0.49 \\
\hline
\end{tabular}

a Standard deviations are calculated from three point on sample.

Because the values obtained from EDX technique may not be correct compared to bulk technique, i.e. ICP. The average values and standard deviation must be used to identify the content of $\mathrm{Al}$ on support. Results showed that the amounts of $[\mathrm{Al}]_{\mathrm{MAO}}$ on mesoporous titania supports from EDX technique were ranged from ca. 6 to $8.5 \%$. Sample B exhibited the highest ratio of Al content and Ti content as seen from Table 2.

The surface property of $\mathrm{MAO} / \mathrm{TiO}_{2}$ support was also proven by XPS. The XPS results are shown in Table 3. It is known that the XPS analysis can detect the species at 1-3 nm depth from surface, whereas the EDX method essentially measures the species up to $5 \mu \mathrm{m}$ from the surface. Therefore, the results of XPS technique represented the surface profile of supports. It was found that mostly the $[\mathrm{Al}]_{\mathrm{MAO}}$ was located on the suface of support. The similar trend was obseved as seen in EDX results where sample B (highest surface area) exhibited the largest amount of $[\mathrm{Al}]_{\mathrm{MAO}}$ and sample $\mathrm{C}$ had the lowest amount of of $[\mathrm{Al}]_{\mathrm{MAO}}$. In general, the cocatalyst (MAO) can be well dispersed in the high surface area support (sample B). However, in case of sample $\mathrm{C}$, the interaction of the cocatalyst and support may be more pronouced. As mentioned, the $[\mathrm{Al}]_{\mathrm{MAO}} /[\mathrm{Ti}]_{\text {support }}$ ratios obtained from XPS were larger than those obtained from EDX indicating that the $[\mathrm{Al}]_{\mathrm{MAO}}$ was abundant on the surface of sample.

Table 3. Elemental analysis of $\mathrm{Al}$ and Ti obtained from XPS.

\begin{tabular}{lccc}
\hline Support used & $\begin{array}{c}{[\mathrm{Al}]_{\text {MAO }}} \\
(\% \text { atomic })\end{array}$ & $\begin{array}{c}{[\mathrm{Ti}]_{\text {support }}} \\
(\% \text { atomic })\end{array}$ & {$[\mathbf{A l}]_{\text {MAO }} /[\mathbf{T i}]_{\text {support }}$} \\
\hline A & 19.14 & 0.34 & 56.29 \\
B & 20.67 & 0.35 & 59.06 \\
C & 17.18 & 2.54 & 6.76 \\
\hline
\end{tabular}

In this study, the polymerization activities of copolymerization of ethylene/1-olefin such as 1-hexene and 1-octene upon the presence of different $\mathrm{MAO} / \mathrm{TiO}_{2}$ supports were measured. In each experiment, the $[\mathrm{Al}]_{\mathrm{MAO}} /[\mathrm{Zr}]_{\text {catatyst }}$ ratios were kept constant at 1135 by fixing the amount of catalyst and varying the amount of $\mathrm{MAO} / \mathrm{TiO}_{2}$ support. The amount of $[\mathrm{Al}]_{\mathrm{MAO}}$ used for calculation was based on the amount of it present as measured by EDX since it is more close to that in bulk. The polymerization activities of the different $\mathrm{MAO} / \mathrm{TiO}_{2}$ supports are listed in Table 4. 
Table 4. Copolymerization activities of different $\mathrm{MAO} / \mathrm{TiO}_{2}$ supports.

\begin{tabular}{|c|c|c|c|c|}
\hline $\begin{array}{l}\text { Support } \\
\text { used }\end{array}$ & Copolymerization & $\begin{array}{l}\text { Time } \\
\text { (s) }\end{array}$ & $\begin{array}{c}\text { Polymer yield } \\
\text { (g) }\end{array}$ & $\begin{array}{l}\text { Catalytic activity }^{\mathrm{a}} \\
\text { [kg pol./mol.Zr.h] }\end{array}$ \\
\hline \multirow{2}{*}{ A } & Ethylene/1-hexene (EH) & 101 & 0.227 & 5,398 \\
\hline & Ethylene/1-octene (EO) & 78 & 0.257 & 7,907 \\
\hline \multirow{2}{*}{ B } & Ethylene/1-hexene (EH) & 81 & 0.309 & 9,143 \\
\hline & Ethylene/1-octene (EO) & 68 & 0.360 & 12,683 \\
\hline \multirow{2}{*}{$\mathrm{C}$} & Ethylene/1-hexene (EH) & 159 & 0.108 & 1,636 \\
\hline & Ethylene/1-octene (EO) & 90 & 0.165 & 4,394 \\
\hline
\end{tabular}

It can be observed that activities of copolymerization obtained from both 1-hexene and 1-octene were in the similar trend. The activities were in the order of sample B> sample A> sample C. Among the supports, the polymerization activity of sample B was the highest that may presume more high activity owing to more dispersion of the catalyst precursor. As seen from EDX and XPS, the high ratio of $[\mathrm{Al}]_{\mathrm{MAO}} /[\mathrm{Ti}]_{\text {support }}$ apparently resulted in high activity. Thus, the activity results are in agreement with the amount of $[\mathrm{Al}]_{\text {MAO }}$ present in each titania support. In addition, the effect of 1-olefin indicated that the activity of $\mathrm{EO}$ was higher than that of $\mathrm{EH}$ copolymerization. This result is consistent with the results reported by other researchers [9-11]. The result also explained that the chain length of the $\alpha$-olefin has a little influence on the comonomer incorporation [12]. It discovered that the catalyst activity of 1-octene system was higher than 1-hexene system due to the higher boiling point of 1-octene (b.p. of 1-octene $=122$ ${ }^{\circ} \mathrm{C}$, b.p. of 1 -hexene $=63^{\circ} \mathrm{C}$ ), which kept higher concentration of 1 -octene in the reaction solution. 1 Octene concentration in the liquid phase was higher than 1-hexene, which resulted in the higher polymerization activity [13].

The quantitative analysis of triad distribution for all copolymers was conducted on the basis assignment of the ${ }^{13} \mathrm{C}$ NMR spectra of ethylene/1-olefin copolymer and calculated according to the method of Randall. The characteristics of ${ }^{13} \mathrm{C}$ NMR spectra for all copolymers were similar indicating the copolymer of ethylene/ 1-olefin (not shown). The melting temperature $\left(\mathrm{T}_{\mathrm{m}}\right)$ for $\mathrm{EH}$ and $\mathrm{EO}$ was obtained from DSC indicating that $\mathrm{EH}$ copolymer exhibited higher $\mathrm{T}_{\mathrm{m}}\left(120^{\circ} \mathrm{C}\right)$ than that of $\mathrm{EO}$ copolymer $\left(97^{\circ} \mathrm{C}\right)$. This indicates higher incorporation of 1-octene in the polymer backbone [14]. The morphologies of copolymer obtained were also similar and replicated the support morphology as well.

\section{Conclusion}

The mesoporous titinia having different surface areas was produced by a catalyzed hydrolysis and polycondensation reactions with different hydrolysis ratio $\left(\mathrm{H}_{2} \mathrm{O} / \mathrm{Ti}\right)$. They were used as support for impregnation with $\mathrm{MAO}$ along with zirconocene catalyst for ethylene/1-olefin copolymerization. It revealed that the titania support having high ratio of $[\mathrm{Al}]_{\mathrm{MAO}} /[\mathrm{Ti}]_{\text {support }}$ apparently resulted in high activity. This is due to different interaction and surface area of the titania support used. Thus, the polymerization activities were in the order of sample B > sample A > sample $\mathrm{C}$ due to the better dispersion of the catalyst precursor. The activity of ethylene/1-octene was higher than that of ethylene/1-hexene copolymerization. Besides, different comonomers (EH and EO) exhibited the different melting temperatures. There was no significant changes in other polymer properties upon different mesoporous $\mathrm{TiO}_{2}$.

\section{Acknowledgement}

The authors thank the Thailand Research Fund (TRF), Higher Education Promotion and National Research University Development (AM1088A), and Office of the Higher Education Commission (CHE) for the financial support of this project. 


\section{References}

[1] P. Svoboda, D. Svobodova, P. Slobodian, T. Ougizawa, and T. Inoue, "Crystallization kinetics of polypropylene/ethylene-octane copolymer blends," Polym. Testing, vol. 28, pp. 215-222, 2008.

[2] W. Kaminsky and A. Laban, "Metallocene catalysis," Appl. Catal. A: Gen., vol. 222, pp. 47-61, 2001.

[3] S. Jiamwijitkul, B. Jongsomjit, and P. Praserthdam, "Effect of boron-modified MCM-41-supported dMMAO/zirconocene catalyst on copolymerization of ethylene/1-octene for LLDPE synthesis," Iran. Polym. J., vol. 16, pp. 549-559, 2007.

[4] S. Bunchongturakarn, B. Jongsomjit, and P. Praserthdam, "Impact of bimodal pore MCM-41supported zirconocene/dMMAO catalyst on copolymerization of ethylene/1-octene," Catal. Commun., vol. 9, pp. 789-795, 2008.

[5] F. Ciardelli, A. Altomare, and M. Michelotti, "From homogeneous to supported metallocene catalysts," Catal. Today, vol. 41, pp. 149-157, 1998.

[6] E. Chaichana, T. Shiono, P. Praserthdam, and B. Jongsomjit, "A comparative study of in situ and ex situ impregnation for LLDPE/silica composites production," Eng. J., vol. 16, pp. 27-36, 2012.

[7] D. Huang, G. S. Luo, and Y. J. Wang, "Using phosphoric acid as a catalyst to control the structures of mesoporous titanium dioxide materials," Micropor. Mesopor. Mater., vol. 84, pp. 27-33, 2005.

[8] K. V. Baiju, S. Shukla, K. S. Sandhya, J. James, and K. G. K. Warrier, "Photocatalytic activity of solgel-derived nanocrystalline titania," J. Phys. Chem. C:, vol. 111, pp. 7612-7622, 2007.

[9] K. Nomura, T. Komatsu, and Y. Imanishi, "Polymerization of 1-hexene, 1-octene catalyzed by $\mathrm{Cp}^{\text {' }} \mathrm{TiCl}_{2}\left(\mathrm{O}-2,6-\mathrm{Pr}_{2} \mathrm{C}_{6} \mathrm{H}_{3}\right)-\mathrm{MAO}$ system: unexpected increase of the catalytic activity for ethylene/1hexene copolymerization by $\left(1,3-{ }^{-} \mathrm{Bu}_{2} \mathrm{C}_{5} \mathrm{H}_{3}\right) \mathrm{TiCl}_{2}\left(\mathrm{O}-2,6-\mathrm{Pr}_{2} \mathrm{C}_{6} \mathrm{H}_{3}\right)-\mathrm{MAO}$ catalyst system," J. Mol. Catal. A: Chem., vol. 152, pp. 249-252, 2000.

[10] K. Nomura, K. Oya, and Y. Imanishi, "Ethylene/ $\alpha$-olefin copolymerization by various nonbridged (cyclopentadienyl)(aryloxy)titanium)(IV) complexes-MAO catalyst system," J. Mol. Catal. A: Chem., vol. 174, pp. 127-140, 2001.

[11] T. Pothirat, B. Jongsomjit, and P. Praserthdam, "A comparative study of $\mathrm{SiO}_{2}$ - and $\mathrm{ZrO}_{2}$ - supported zirconocene/MAO catalysts on ethylene/1-olefin copolymerization," Catal. Commun., vol. 9, pp. 14261431, 2008.

[12] M.-L. Gao, Y.-F. Gu, C. Wanga, X.-L. Yao, X.-L. Sun, C.-F. Li, C.-T. Qian, B. Liu, Z. Ma, Y. Tang, Z. Xie, S.-Z. Bu, and Y. Gao, "Ethylene homopolymerization and copolymerization with $\alpha$-olefins catalyzed by titanium complexes bearing [O-NSR] tridentate ligands," J. Mol. Catal. A: Chem., vol. 292, pp. 62-66, 2008.

[13] K. T. Li, C. L. Dai, and C. Y. Li, "Synthesis of linear density polyethylene with a nano-sized silica supported Cp $\mathrm{ZrCl}_{2} / \mathrm{MAO}$ catalyst," Polym Bull., vol. 64, pp. 749-759, 2008.

[14] M. V. Marques, O. F. C. da Silva, A. C. S. L. S Coutinho, and A. S. de Araujo, "Ethylene polymerization catalyzed by metallocene supported on mesoporous materials," Polym. Bull., vol. 61, pp. 415-423, 2008. 
